\title{
AN INEQUALITY FOR THE INTEGRAL MEANS \\ OF A HADAMARD PRODUCT
}

\author{
MIROSLAV PAVLOVIĆ
}

(Communicated by Irwin Kra)

ABSTRACT. Motivated by Colzani's paper [1] we prove that

$$
M_{q}(r, f * g) \leq(1-r)^{1-1 / p}\|f\|_{p}\|g\|_{q}, \quad 0<r<1,
$$

where $0<p<1, p \leq q \leq \infty$ and $f * g$ is the Hadamard product of $f \in H^{p}$ and $g \in H^{q}$.

For a function $F$, continuous in the disc $U=\{z:|z|<1\}$ let

$$
\begin{aligned}
& M_{p}^{p}(r, F)=\frac{1}{2 \pi} \int_{0}^{2 \pi}\left|F\left(r e^{i t}\right)\right|^{p} d t, \quad 0<p<\infty, \\
& M_{\infty}(r, F)=\max _{0 \leq t<2 \pi}\left|F\left(r e^{i t}\right)\right|,
\end{aligned}
$$

where $0 \leq r<1$. The Hardy class $H^{p}$ consists of those $f$ which are analytic in $U$ and satisfy the condition

$$
\|f\|_{p}:=\sup _{0<r<1} M_{p}(r, f)<\infty .
$$

If $f(z)=\sum a_{n} z^{n}$ and $g(z)=\sum b_{n} z^{n}$ are analtyic in $U$, then their Hadamard product $f * g$, defined by

$$
(f * g)(z)=\sum_{n=0}^{\infty} a_{n} b_{n} z^{n}
$$

is analytic in $U$. It is well known that if $f \in H^{1}$ and $g \in H^{q}, q \geq 1$, then $M_{q}(r, f * g) \leq\|f\|_{1}\|g\|_{q}(0<r<1)$ and consequently $f * g \in H^{q}$. This fact is generalized by the following theorem.

THEOREM. Let $f \in H^{p}$ and $g \in H^{q}$, where $0<p \leq 1$ and $p \leq q<\infty$. Then

$$
M_{q}(r, f * g)=O\left((1-r)^{1-1 / p}\right), \quad r \rightarrow 1^{-},
$$

and,

$$
M_{q}(r, f * g) \leq(1-r)^{1-1 / p}\|f\|_{p}\|g\|_{q}, \quad 0<r<1 .
$$

For the proof we need a familiar lemma.

Received by the editors March 30, 1987.

1980 Mathematics Subject Classification (1985 Revision). Primary 30A10, 30D55.

Key words and phrases. Integral means, Hadamard product.

(C) 1988 American Mathematical Society $0002-9939 / 88 \$ 1.00+\$ .25$ per page 
LEMMA. If $F \in H^{p}, 0<p \leq 1$, then

$$
M_{1}(r, F) \leq\left(1-r^{2}\right)^{1-1 / p}\|F\|_{p}, \quad 0<r<1 .
$$

Proof. Since

$$
M_{1}(r, F) \leq M_{\infty}^{1-p}(r, F) M_{p}^{p}(r, F)
$$

we have to prove that

$$
M_{\infty}(r, F) \leq\left(1-r^{2}\right)^{-1 / p}\|F\|_{p} .
$$

This is reduced to the case $p=2$ in the standard way (see [2]). Let $F(z)=\sum c_{n} z^{n}$ belong to $H^{2}$. Then

$$
\begin{aligned}
M_{\infty}^{2}(r, F) & \leq\left(\sum_{0}^{\infty}\left|c_{n}\right| r^{n}\right)^{2} \\
& \leq \sum_{0}^{\infty}\left|c_{n}\right|^{2} \sum_{0}^{\infty} r^{2 n}=\|F\|_{2}^{2}\left(1-r^{2}\right)^{-1}
\end{aligned}
$$

and this concludes the proof.

PROOF OF THE THEOREM. It is easily shown that $f$ and $g$ may be supposed to be analytic in the closed disc. By Parseval's formula

$$
h\left(r^{2} w\right):=(f * g)\left(r^{2} w\right)=\frac{1}{2 \pi} \int_{0}^{2 \pi} f\left(r e^{-i t}\right) g\left(r e^{i t} w\right) d t, \quad|w|=1
$$

whence

$$
\begin{aligned}
\left|h\left(r^{2} w\right)\right| & \leq \frac{1}{2 \pi} \int_{0}^{2 \pi}\left|\overline{f\left(r e^{-i t}\right)}\right|\left|g\left(r e^{i t} w\right)\right| d t \\
& =\frac{1}{2 \pi} \int_{0}^{2 \pi}\left|F\left(r e^{i t}\right)\right| d t=M_{1}(r, F)
\end{aligned}
$$

where

$$
F(z)=\overline{f(\bar{z})} g(z w), \quad|z| \leq 1 .
$$

Since $f$ is analytic in the closed unit disc we may apply the lemma to obtain

$$
\begin{aligned}
& \left(1-r^{2}\right)^{1-p}\left|h\left(r^{2} w\right)\right|^{p} \leq\|F\|_{p}^{p} \\
& \quad=\frac{1}{2 \pi} \int_{0}^{2 \pi}\left|f\left(e^{-i t}\right)\right|^{p}\left|g\left(e^{i t} w\right)\right|^{p} d t .
\end{aligned}
$$

Hence, by Minkowski's inequality (in continuous form),

$$
\begin{aligned}
& \left(1-r^{2}\right)^{1-p} M_{s}\left(r^{2},|h|^{p}\right) \\
& \quad \leq \frac{1}{2 \pi} \int_{0}^{2 \pi}\left|f\left(e^{-i t}\right)\right|^{p} d t\left\{\frac{1}{2 \pi} \int_{0}^{2 \pi}\left|g\left(e^{i t} e^{i \theta}\right)\right|^{p s} d \theta\right\}^{1 / s},
\end{aligned}
$$

where $s \geq 1$. By taking $s=q / p$ we get

$$
\left(1-r^{2}\right)^{1-p} M_{q}^{p}\left(r^{2}, h\right)=\left(1-r^{2}\right)^{1-p} M_{s}\left(r^{2},|h|^{p}\right) \leq\|f\|_{p}^{p}\|g\|_{q}^{p},
$$

and this concludes the proof. 


\section{REFERENCES}

1. L. Colzani, Cesàro means of power series, Bull. Un. Mat. Ital. A (6) 3 (1984), 147-149.

2. P. L. Duren, Theory of $H^{p}$ spaces, Academic Press, New York, 1970.

Prirodno-MatematičKi FakUltet, Institut za MATEMatiku 11000 Beograd, YUGOSLAVIA 